\title{
BLOG CUIRLATINEDECOLONIAL: CARTOGRAFIAS ARTÍSTICAS DESDE 0 SUL GLOBAL
}

AUTOR: PEDRO HENRIQUE PEREIRA SANTOS

CO-AUTOR/ORIENTADOR: RAFAEL SIQUEIRA DE GUIMARAES

Resumo: Este projeto, em linhas gerais, teve como objetivos: Realizar uma cartografia de artistas latinoamericanes que possuíssem dentro da nossa proposta a performance cuir; a partir de estudos com base em Preciado, analisar essas suas propostas artísticas, por meio da analítica de sua performatividade analisar suas proposições estéticas por meio da análise de suas entrevistas públicas, e criar uma plataforma web para conexão tanto entre artistes Cuir quanto com o público. Partindo de estudos posteriores podendo cristalizar ainda mais a perspectiva de necessidade do artivismo que estes artistes fazem como forma de modificar sua vida e também de sobrevivência, mostrar (re)existência, para poder existir. O plano de trabalho inicial se insere neste projeto maior, que consiste em realizar o levantamento de materiais artísticos de forma cartográfica, sendo realizada em grupo de pesquisa para disponibilização numa plataforma web, aqui escolhida na forma de blog, https://territoriocuir.wixsite.com/territoriocuir, tanto com o material artístico e ativismo de cada artista escolhido, quanto a apreciação crítica.

Palavras-chave: Blog, Cuir, Arte. 